\title{
Stress-strain state of the "combined tower- reinforced concrete foundation-foundation soil" system for high-rise structures
}

\author{
Levon Mailyan ${ }^{1}$, Serdar Yaziev ${ }^{1}$, Linar Sabitov*,2, Yuriy Konoplev², Oleg Radaykin ${ }^{3}$ \\ ${ }^{1}$ Don State Technical University, 344002, Rostov-on-Don, Russia \\ ${ }^{2}$ Kazan (Volga region) Federal University, 420008, Kazan, Russia \\ ${ }^{3}$ Kazan state university of architecture and civil engineering, 420043, Kazan, Russia
}

\begin{abstract}
The aim of the work was to evaluate the effectiveness of the "combined tower-reinforced concrete foundation-foundation soil" system for high-rise structures on the example of a wind power plant (wind turbine) with a capacity of 1.5-2.0 MW using computer modeling in the PC "Ansys". Thus, under the combined tower the article refers to a high-rise building, consisting of two parts: the lower composite, the upper - in the form of a thin-walled core-shell closed profile. In both cases, the shell is a pipe with a weak taper. As an analogue, the VEU considered in foreign literature is adopted: the radius of the rotor is $\mathrm{R}=41 \mathrm{~m}$, the height to the axis of the wind wheel is Zhub $=80 \mathrm{~m}$, the shell is made of high-strength C355 steel and unlike the analog in this work the cavity of the tower lower part to a height of $20 \mathrm{~m}$ was filled with B60 class concrete. The modeling took into account the spatial work of the elements of the structural system and the physical nonlinearity of the materials from which they are made. At the same time, the Mises strength theory was used for steel, the Williams - Varnake theory - for concrete, and the Drukker - Prager theory - for the foundation soil. Comparison of the calculation results with the analogue showed that the destructive load of the tower increased by $37 \%$ due to filling the lower part of it with concrete, which indicates the effectiveness of the proposed solution. In this case, the destruction of the tower with a concrete core and without it occurred from the loss of steel shell local stability at the level of the tower junction with the foundation (with a compressed zone).
\end{abstract}

\section{Introduction}

This article discusses the joint static operation of the elements of the "combined towerreinforced concrete foundation-foundation soil" construction system using an example of a wind power installation. At the same time, the combined tower in the article is a high-rise structure consisting of two parts: the lower one is pipe-concrete, the upper one is in the form of a thin-walled rod-shell of a closed profile. In both cases, a pipe with a weak taper acts as a shell. An analysis of the literature showed that a holistic methodology for

*Corresponding author: sabitov-kgasu@mail.ru 
calculating such a system is currently missing. And when developing it, the following factors should be taken into account most fully:

- physical nonlinearity of material properties;

- geometric non-linearity of system elements (blades, etc.);

- cyclic fatigue of materials - steel and concrete;

- dynamic effects;

- resonant phenomena;

- friction between concrete and steel shell, as well as between concrete and soil.

To analytically describe the influence of all these factors completely is not yet possible, which is reflected in existing standards on the wind turbines' design [1,2] and educationmethodical resources [3]. However, a powerful tool can be used for this - computer simulation in PC “Ansys". In the article [4], this tool was already used by us to study the joint work of the system "steel support of power lines - foundation - foundation soil". Moreover, in contrast to it, the following features are taken into account in the system considered here:

- the wind load on the surfaces of the rotating blades sweeping, the important

characteristic of which is not pressure, but the speed of the wind flow;

- the concrete presence at the bottom part of the tower;

- friction forces between the steel shell and the concrete core.

The last two circumstances turn the lower part of the tower barrel into the so-called pipe-concrete structure, which, due to a number of advantages [5,6], significantly increases the operational properties of wind turbines, including strength, reliability and durability. The use of pipe concrete as a part of a combined wind turbine tower, apparently, is proposed here for the first time.

Along with the advantages, pipe concrete also has disadvantages, which nevertheless are easily eliminated with minimal additional costs. The most significant drawback is the difficulty in ensuring the joint operation of the concrete core and the outer steel shell at operational loads. Due to the difference in the lateral deformation coefficients of concrete and steel $\left(v_{\mathrm{b}} \approx 0,18 \div 0,25, v_{\mathrm{s}} \approx 0,3\right)$, under these conditions, the concrete core and steel cage work inefficiently. To eliminate this drawback of pipe concrete, the following solutions can be applied (both separately and in combination): weld special steel anchors on the inner surface of the pipe-shell; use expanding non-shrink cement for the manufacture of concrete mix; to make a pipe-concrete structure of circular section: with an external and internal shell of a steel pipe with filling the space between them with concrete.

\section{Materials and methods}

As an example, let us consider Acciona AW-82/1500 wind turbine, IEC IIIB class at 1.5-2 MW from [7, 8] (refer with Fig. 1). 

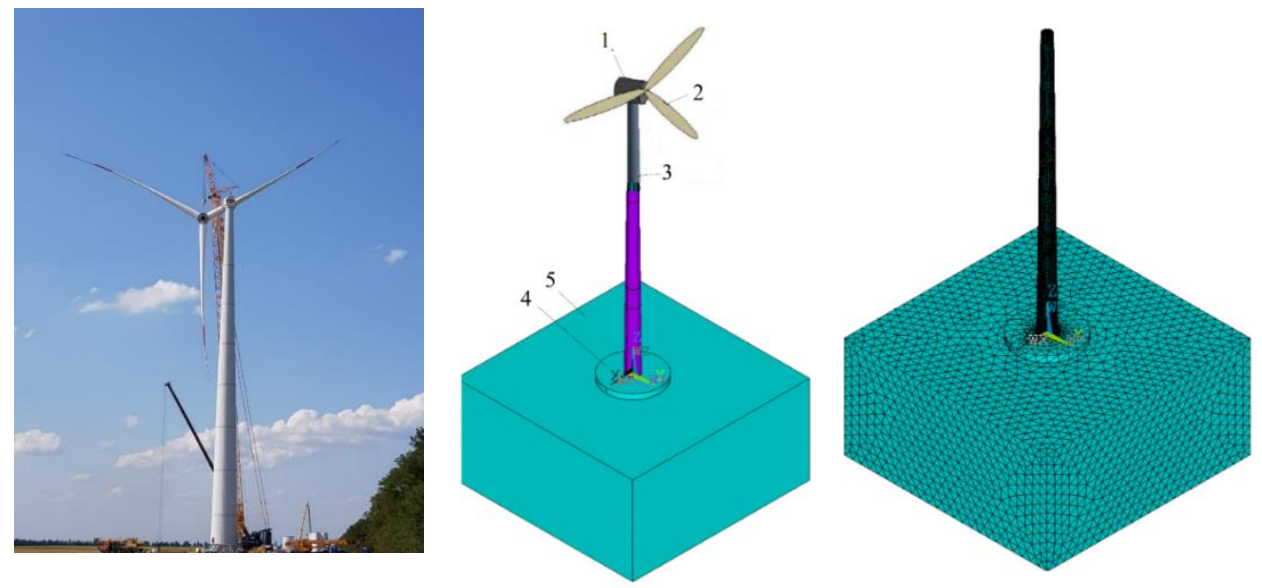

Fig. 1. Structural diagram (computer model in PC “Ansys”) of a $2 \mathrm{MW}$ wind turbine:

1 - gondola; 2 - rotor blades; 3 - tower; 4 - dismountable foundation; 5 - base soil

The instalation has the following characteristics: rotor radius $-\mathrm{R}=41 \mathrm{~m}$, swept area $-\mathrm{S}$ $=5345 \mathrm{~m}^{2}$, height to the axis of the wind wheel $-z_{h u b}=80 \mathrm{~m}$, height to the gondola bottom - $76.7 \mathrm{~m}$ (tower height), mass of each blade - $5.78 \mathrm{t}$ (total 3 pcs.), rotor mass - $32.34 \mathrm{t}$, gondola mass $-52.5 \mathrm{t}$; the wind turbine tower is made in the form of a thin-walled rod-shell of a closed profile, has a weak taper and consists of three parts of equal height, connected by flanges, the wall thickness of each part is different: lower $-t_{1}=30 \mathrm{~mm}$, middle $-t_{2}=25$ $\mathrm{mm}$ and upper $-t_{3}=15 \mathrm{~mm}$, the tower has a cross-sectional diameter along the outer perimeter at the bottom - $D_{1}=4.3 \mathrm{~m}$, at the top - $D_{2}=2.6 \mathrm{~m}$. The tower shell is made of high-strength steel C355. In contrast to the analogue [7.8] in this work, the cavity of the lower part of the tower to a height of $20 \mathrm{~m}$ is filled with concrete of class B60. To avoid squeezing concrete up during deformation, a steel plate $50 \mathrm{~mm}$ thick and $3.0 \mathrm{~m}$ in diameter was made above its surface, which is rigidly connected to the walls of the tower shell.

The foundation under the tower is adopted as massive because of B25 class monolithic concrete, reinforced with steel reinforcement. In plan there is a foundation of a circular cross section.

Base soils at the supports' installation site can be different, we will take the worst case scenario that SP 22.13330.2011 "Foundations of buildings and structures" allows: the type of soil is clay, non-slip, non-swellable; porosity coefficient 0.95 ; strain modulus $E=8$ $\mathrm{MPa}$; liquidity rate $I_{L}=0.5$; soil adhesion $c=15 \mathrm{kPa}$; angle of internal friction $\varphi=170$; rated resistance $R_{0}=150 \mathrm{kPa}$; the coefficient of the base stiffness (coefficient of subgrade resistance ) $k=10 \mathrm{MPa} / \mathrm{m}$ (Designer book. T.2, edited by A. Umansky, 1973. - p. 307). In this case, the soil mass in the model was adopted with dimensions of $60 \times 60 \times 30 \mathrm{~m}$, which, as calculations have shown, is sufficient to determine the depth of the compressible thickness and to exclude the influence of the model boundary conditions on the stressed and strained state (SSS) of the soil directly under the foundation. 
a

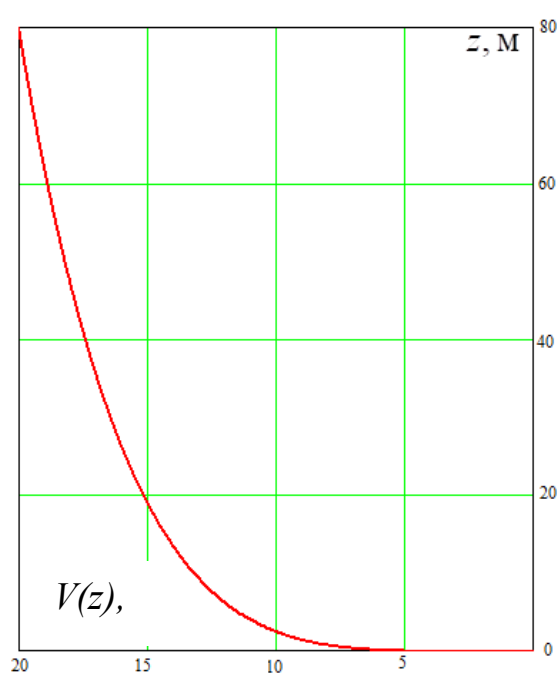

$\mathrm{b}$

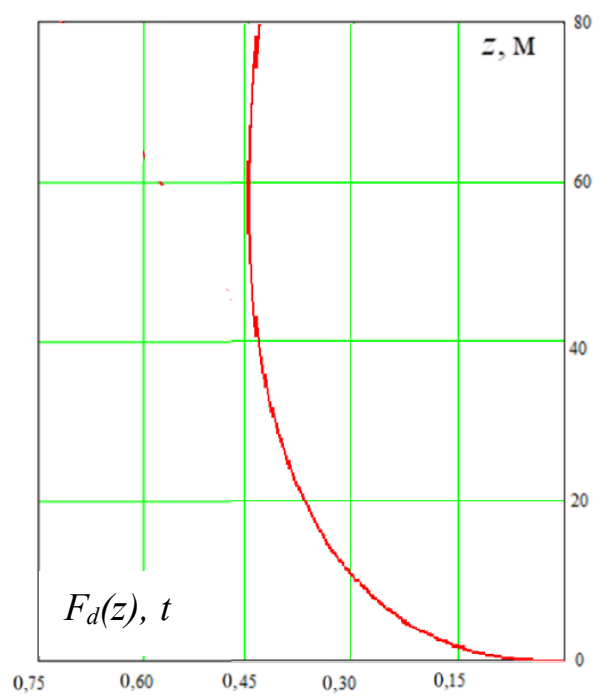

Fig. 2. Wind speed V (a) and wind load (b) distribution in height

\section{Results and discussion}

The loads acting on the wind turbine design are adopted taking into account the safety factors for the load $\gamma_{f}=1,0$ and the responsibility of the structure $\gamma_{n}=1,0$. In Table 2 GOST R 54418.1-2012 prescribed 8 design cases for the wind turbines' calculation. The most characteristic is the first - "Power Generation" - calculation using the normal turbulence model. To reduce the amount of computation, we consider only this design case ( $\left.V_{\text {in }}<V_{\text {hub }}<V_{\text {out }}\right)$ :

- dead weight of the tip: $P_{1}=5.78 \times 3+32.34+52.5=102.2 \mathrm{t}$ (applied at the top);

- dead weight of the steel tower shell: $P_{2}=135 \mathrm{t}$ (evenly distributed in height and automatically taken into account in the program when setting the density of the material and gravity);

- dead weight of concrete filling the bottom of the tower: $P_{3}=491 \mathrm{t}$ (evenly distributed in height and taken into account in the program automatically);

- the speed of the incident air flow at the height of the axis of the wind wheel (for wind turbines with a horizontal axis of rotation) $-V_{h u b}=20 \mathrm{~m} / \mathrm{s}$;

- average wind speed - $V_{\text {ave }}=7.5 \mathrm{~m} / \mathrm{s}$;

- maximum average wind speed (determined with a measurement interval of 10 minutes and not exceeding its value for 50 years) $-V_{\text {ref }}=37.5 \mathrm{~m} / \mathrm{s}$;

- launching wind speed - $V_{\text {in }}=3 \mathrm{~m} / \mathrm{s}$;

- restart wind speed - $V_{\text {out }}=20 \mathrm{~m} / \mathrm{s}$;

- extreme speed of a wind gust (determined with a measurement interval of 3 seconds and not exceeding its value for 50 years) $-V_{e 50}=52.5 \mathrm{~m} / \mathrm{s}$;

- horizontal traction force caused by a wind flow running onto the blades: $F_{t}=\frac{1}{2} \rho V_{h u b}^{2} C_{T} \pi R^{2}=80.5 m$ (calculated at an air density of $\rho=\frac{353}{273+t{ }^{0} \mathrm{C}}=1.169$

$\mathrm{kg} / \mathrm{m}^{3}$, the calculated air temperature of the warm period of the year with a security 
of $0.95-t=29{ }^{0} \mathrm{C}$ and a safety coefficient [8] - $C_{T}=0.64$ (at domestic researchers recommend $\left.C_{T}=1.4[9]\right)$ );

- model of the normal wind profile [1.8] - profile of the wind load along the height of the structure (Fig. 2, a):, $V(z)=V_{h u b}\left(\frac{z}{z_{h u b}}\right)^{\alpha}=20 \cdot\left(\frac{z}{80}\right)^{0,2}$ where $\mathrm{z}$ is the vertical coordinate; $\alpha$ is an exponent, $\alpha=0.2$.

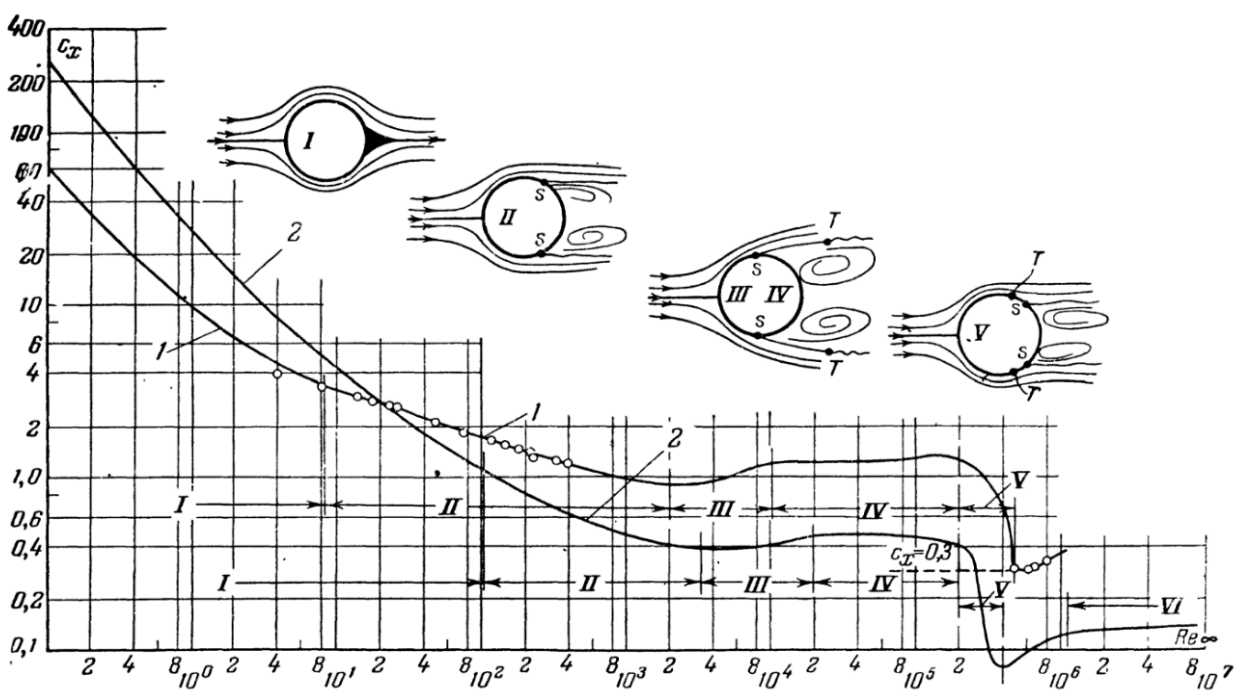

The most complete dependence of the drag coefficient for the cylinder (1) and sphere (2) on the Reynolds number [11]

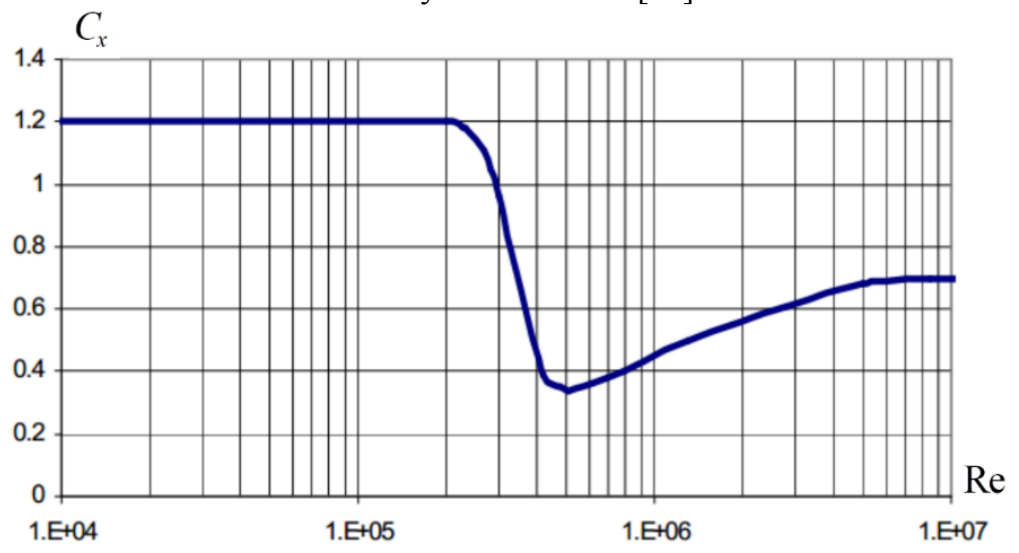

Simplified dependency $C_{x}(\mathrm{Re})$ for cylinder [12]

Fig. 3. The dependence of the drag coefficient on the Reynolds number

- the wind load distribution profile of the tower corresponding to this model (Fig. 2, b) $F_{d}(z)=\frac{1}{2} \rho V(z)^{2} C_{x} D(z)$ : where $D(z)$ is the outer diameter of the cross-section, variable in height of the tower, $D(z)=D_{2}+\left(D_{1}-D_{2}\right)\left(1-\frac{z}{z_{h u b}}\right) ; C_{x}$ - drag coefficient for 
the cylinder, depending on the Reynolds number, $\operatorname{Re}(z)=\frac{\rho V(z) D(z)}{\mu}=0 . .5 .414 \cdot 10^{6}$ $\mu$ - dynamic air viscosity coefficient, which is more dependent on temperature $t,{ }^{\circ} \mathrm{C}$, and to a lesser extent on pressure $p, \quad \mathrm{~Pa}$ (usually neglected): $\mu=\frac{3}{2} \cdot \frac{(273+t)^{\frac{3}{2}}}{395+t} \cdot 10^{-6}=18.6 \cdot 10^{-6} \mathrm{~Pa} \cdot \mathrm{s}$. For the coefficient $C_{x}$ in Fig. 3 shows a more complete dependence [10] and simplified [11]. The latter is suitable for engineering calculations and is further taken as a basis. Moreover, to simplify the margin of the bearing capacity we will accept $C_{x}=0.7$ - const .

- the torque resulting from a change of the wind direction (applied at the top of the tower), $M_{z, t}=F_{t} r_{0}=146 \mathrm{t} \cdot \mathrm{m}$ where $r_{0}=1.814 \mathrm{~m}$ is the external radius of the cross section averaged over the height of the tower (the adopted coordinate system and force diagram are shown in Fig. 4 according to [3]);

- the gyroscopic moment on the gondola (applied at the top of the tower), $M_{x, g}=\theta_{R} \omega_{R} \omega_{n} \approx 3 m_{b} r_{c}^{2} \omega_{R} \omega_{n}=1290(t \cdot m)$ where $\omega_{R}$ is the current angular velocity of rotor rotation (wind wheel) relative to the $\mathrm{x}$ axis, $\omega_{R}=16.1 \mathrm{rpm}=1.686 \mathrm{rad} / \mathrm{s} ; \omega_{n}$ is the angular velocity of rotation of the nacelle relative to the $z$ axis, $\omega_{n}=1 \mathrm{rpm}=0.105 \mathrm{rad} / \mathrm{s} ; \theta_{R}$ is the polar moment of rotor inertia relative to its rotation axis. For a three-bladed rotor it is determined by the expression: $\theta_{R}=3\left(\theta_{b}+m_{b} r_{c}^{2}\right) \approx 3 m_{b} r_{c}^{2}$, where $\theta_{b}$ is the moment of inertia for the blade mass $m_{b}=5.78 \mathrm{t}$ passing through the center of mass perpendicular to the blade plane, $r_{c}=\frac{R}{2}$ is the distance from the rotation axis of the rotor to the center of blade mass, $r_{c}=20.5 \mathrm{~m}$;

- centrifugal force arising due to the imbalance of the rotor mass $P_{c f}=m_{R} e_{0} \omega_{R}=11.2 \mathrm{t}$, where $m_{R}=32.34 \mathrm{t}$ is the rotor mass, $e_{0}=0,005 R=0.205 \mathrm{~m}$ is the eccentricity; - centrifugal force moments $M_{x, c f}=M_{z, c f}=P_{c f} l=37 t \cdot m$, where $l=3.3 m$ is the distance from the wind wheel axis to the tower top

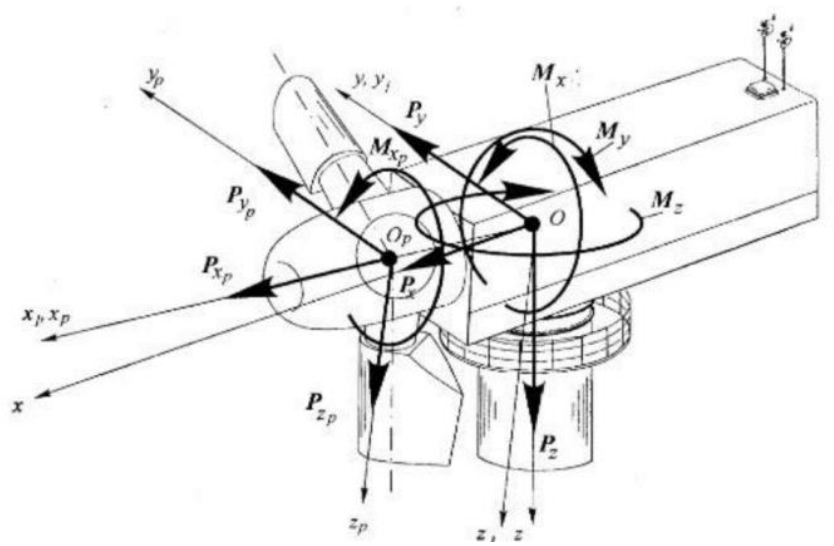

Fig. 4. The coordinate system at the tower top and the scheme of existing efforts [3] 
The structure under consideration includes elements formed from materials with qualitatively and quantitatively different physical and mechanical properties.

Fig. 5 shows the material deformation diagrams used to create the model.

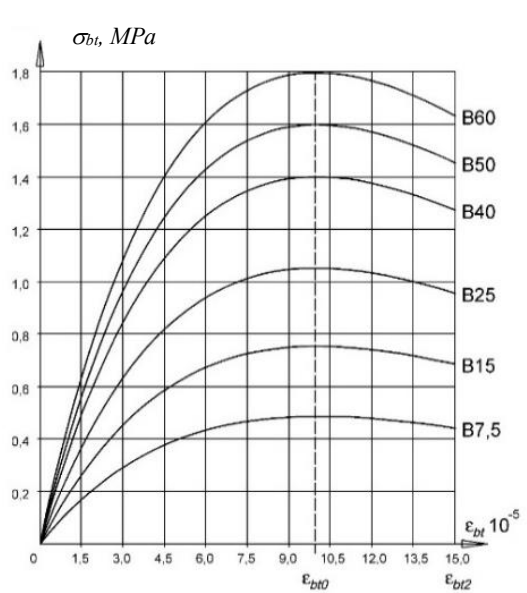

a)

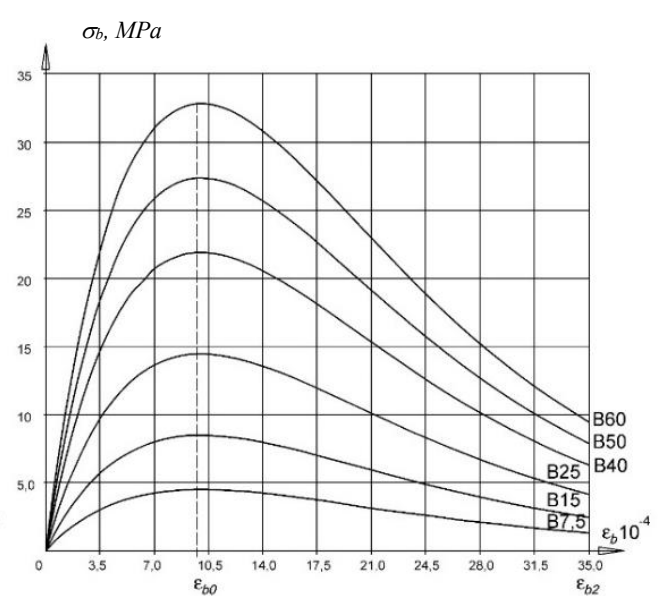

b)

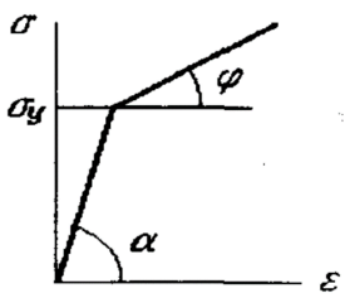

c)

Fig. 5. Diagrams of materials' deformation: a) Radikin O.V. curvilinear diagram under tension [12]; b) also - in compression; c) two-line diagram, kinematic hardening with the Bauschenger effect

The mathematical expressions describing the diagrams in Fig. 2, a-b are given in the article [12]. As a law of steel deformation, a bilinear diagram of kinematic hardening was adopted (see Fig. 5, b). The law assumes that in the " $\sigma-\varepsilon$ " diagram the sum of different signs' stresses during loading and unloading is always equal to twice the yield strength $\sigma_{\mathrm{y}}$, that is, the Bausinger effect is taken into account. The model is recommended for elastoplastic problems with small deformations of a material that follows Mises flow condition.

Thus, the physical law of deformation of a thin-walled shell was described by four parameters: elastic modulus $\mathrm{E}=206 \cdot 10^{3} \mathrm{MPa}$, tangential modulus $E^{\prime}=75 \cdot 10^{3} \mathrm{MPa}$, yield strength $\sigma_{y n}=355 \mathrm{MPa}$ and Poisson's coefficient $\nu=0.3$.

To determine the foundation dimensions, the tower was previously calculated as a rigidly fixed cantilever rack, that is, without taking into account the foundation and foundation soil:

$$
\begin{gathered}
N=P_{1}+P_{2}+P_{3}++P_{c f}=102,2+135+491+11.2=739.4 \mathrm{t} \\
M_{x}=M_{x, g}+M_{x, c f}+F_{t} \times z_{h u b}+\int_{0}^{H_{t}} F_{d}(z) z d z=1290+37+80.5 \times 80+1272=9039 \mathrm{t} \times \mathrm{m} .
\end{gathered}
$$


As a result, loads were obtained on the edge of the foundation, according to which the required foundation dimensions were calculated by using the SP 22.13330.2011 "Foundations of buildings and structures" formulas: $18 \times 18 \mathrm{~m}$, height $1.8 \mathrm{~m}$.

The results of determining the equivalent stresses in the tower are shown in Fig. 6.

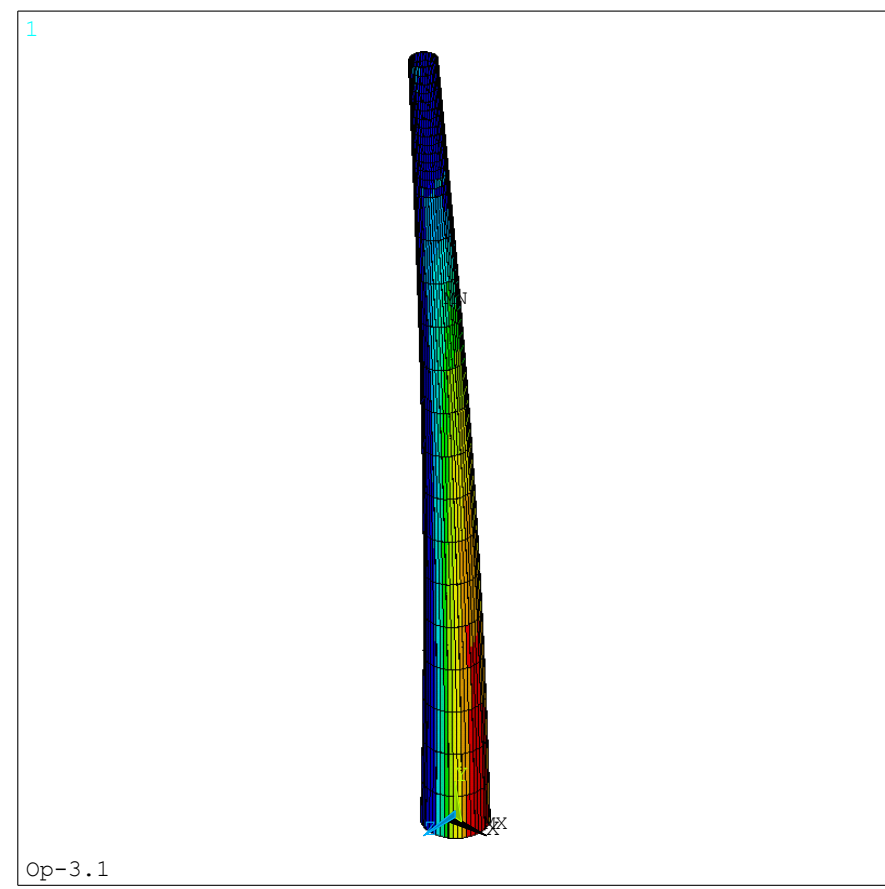

ANSYS 14.5 .7

NODAL SOLUTION

STEP $=1$

SUB $=1$

TIME $=1$

S1

PowerGraphics

EFACET $=1$

AVRES $=$ Mat

$\operatorname{DMX}=24.5058$

SMN $=-.866 \mathrm{E}-05$

SMX $=41.6854$

$-.866 \mathrm{E}-05$

$-.866 \mathrm{E}$
4.6317

9.2634
$\square \quad 13.8951$

18.5268

23.1585

27.7902

32.4219

37.0536

41.6854

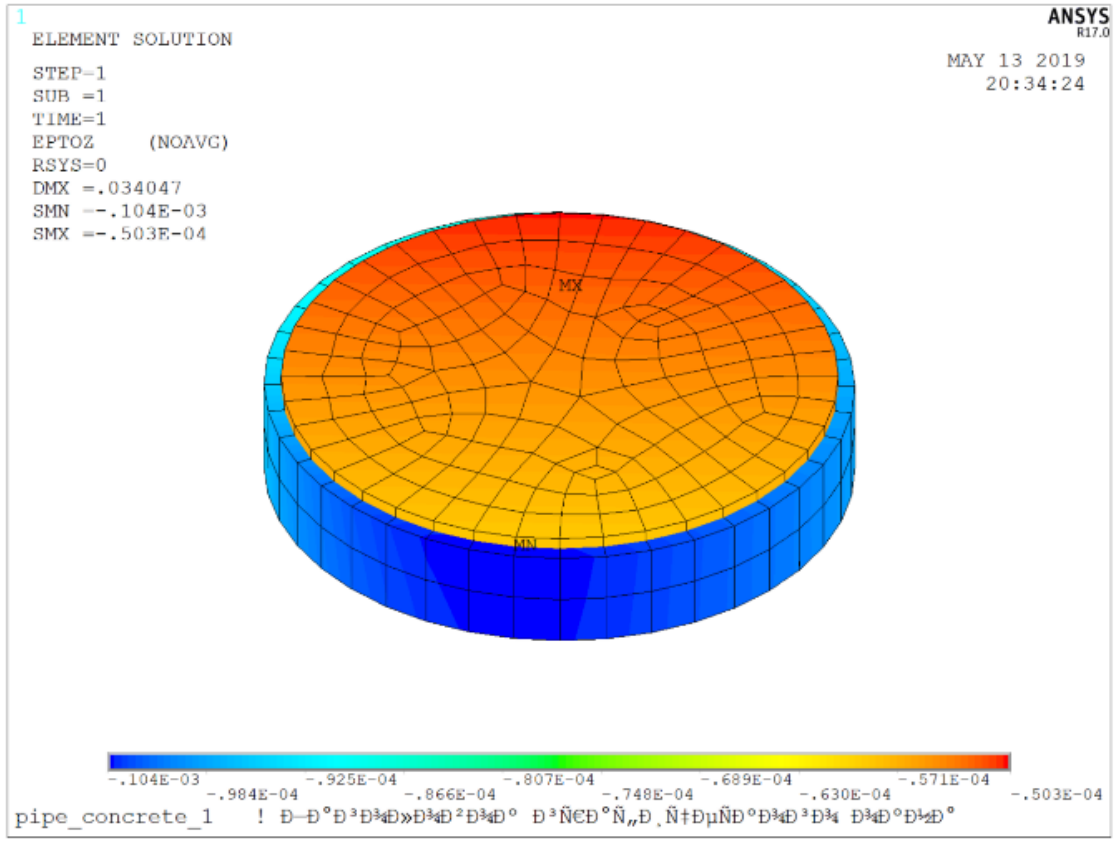

Fig. 6. The results of the tower computer simulation 


\section{Summary}

Comparison of the calculation results with the data [7] showed that the destructive load of the tower increased by $37 \%$ due to filling its lower part with concrete, which indicates the effectiveness of the proposed solution. Moreover, the destruction of the tower with a concrete core and without it occurred from the loss of local stability of the steel shell at the level of the tower junction with the foundation (with a compressed zone). The results obtained on the effectiveness of flexible pipe concrete correlate with the experimental data of [13], which indicates the validity of the approach proposed in this article. Subsequent publications will be devoted to a more detailed consideration of the stressed deformed soil mass, foundation, contact interaction of the concrete core and steel shell.

\section{References}

1. STO 70238424.27.100.059-2009 Wind power stations (WPS). The conditions of creation. Norms and requirements, Moscow: non-profit Partnership "Innovations in the electric power industry", 2009.

2. STO RusHydro 03.01.102-2013 Wind power stations. Main requirements and criteria for selecting wind power equipment for wind farms, Moscow, JSC RUSHYDRO, 2013.

3. V.V. Elistratov, A.A. Panfilov, Design and operation of non-traditional and renewable energy installations. Wind power plants (Polytechnic University Press, St. Petersburg, 2011.

4. Y.M. Strelkov, O.V. Radaykin, L.S. Sabitov, I.L. Kuznetsov, Construction mechanics and calculation of structures, 1, 71-79 (2019).

5. I.A. Duvanova, I.D. Salmanov, Construction of unique buildings and structures, 6 (21), 89-103 (2014).

6. A.I. Kikin, R.S. Sanzharovsky, V.A. Trull, Structures made of steel pipes filled with concrete (Stroizdat, Moscow, 1974).

7. K.N. Umesh, P. Bharath, Farzath Iyaz Mohamed, Design and analysis of 2-MW wind turbine tower, International journal of mechanical and production engineering, 4 (10), 13-17 (2016).

8. Chawin Chantharasenawong, Pattaramon Jongpradist and Sasaraj Laoharatchapruek Preliminary Design of 1.5 MW Modular Wind Turbine Tower, AEC17, 2nd TSME International Conference on Mechanical Engineering 19-21 October 2011.

9. E.M. Fateev, Wind turbines and wind installations (Selhozgiz, Moscow, 1948).

10. M.E. Deitch, Technical gas dynamics (Gosenergoizdat, Moscow-Leningrad, 1961).

11. C. Scruton, E.W.E. Rogers, Steady and Unsteady Wind Loading of Buildings and Structures [and Discussion], Philosophical transactions of the royal society of London, 1971.

12. O.V. Radaykin, Bulletin of civil engineers, St. Petersburg, Spbgasu, 6, 71-78 (2017).

13. V.I. Efimenko, Strength and deformations of bent pipe-concrete elements: Diss. of candidate of technical sciences: 05.23.01, Poltava, 1989, $185 \mathrm{p}$. 